\title{
Gastric Myoelectrical Activity in Patients with Recurrent Gastric or Duodenal Ulcers
}

\author{
Takeshi KAMIYA ${ }^{1}$, Yuka KOBAYASHI ${ }^{1}$, Naoko MISU ${ }^{1}$, Makoto HIRAKO ${ }^{1}$, \\ Hiroshi ADACHI ${ }^{1}$, Toshihiro NAGAO ${ }^{1}$, Michiko SHIKANO ${ }^{1}$, \\ Eriko MATSUHISA ${ }^{1}$, Takashi ANDO ${ }^{1}$ and Genjiro KIMURA ${ }^{1}$ \\ ${ }^{1}$ Department of Internal Medicine and Pathophysiology, Nagoya City University \\ Graduate School of Medical Science, Nagoya 467-8601, Japan
}

\begin{abstract}
The aim of this study was to characterize gastric myoelectrical activity in patients with recurrent gastric ulcer (GU) or duodenal ulcer (DU), and to compare gastric motility between these two groups of patients. Studies were performed in 59 patients with recurrent active peptic-ulcer disease as diagnosed by gastrointestinal endoscopy: 31 patients had a GU and 28 patients had a DU. Gastric myoelectrical activity was evaluated by cutaneous electr-ogastrography (EGG). The following EGG parameters were assessed: the percentage of normogastria (regular 2.4-3.6 cpm slow waves); the EGG power ratio; and the occurrence of a postprandial dip (PD), which is the transient decrease in EGG frequency after a meal. In the GU group, no significant change occurred in the percentage of normogastria or in the EGG power ratio observed after treatment with a proton-pump inhibitor. During the healed stage, the occurrence of PD remained unchanged. In contrast, in the DU group, the percentage of normogastria and the EGG power ratio were significantly increased after treatment. Moreover, during the healed stage, the occurrence of PD significantly increased compared with that during the active stage. These findings suggest that abnormal gastric myoelectrical activity plays an important role in the pathophysiology of recurrent GU rather than DU.
\end{abstract}

Key words: gastric ulcer, duodenal ulcer, gastric myoelectrical activity, electrogastrography

\section{Introduction}

The pathogenesis of the onset of peptic ulcers and their characteristic recurrence has been extensively investigated, but the underlying mechanisms are not yet clearly understood. Various factors contributing to the onset and recurrence of peptic ulcers have been proposed, and recently gastrointestinal motility has been attracting attention as a new contributory factor. However, the results of previous studies which have assessed gastric motility in peptic ulcers

Correspondence to: T. Kamiya, Department of Internal Medicine and Pathophysiology, Nagoya City University Graduate School of Medical Science, 1-Kawasumi, Mizuho-cho, Mizuho-ku, Nagoya 467-8601, Japan

Phone: +81-52-853-8221 Fax: +81-52-852-3796 e-mail: kamitake@med.nagoya-cu.ac.jp 
are conflicting, and the role played by gastric motility in these diseases is still unclear. As recently reported, increases in duodenogastric reflux are associated with gastric ulcer (GU) (Mirada et al., 1985; Fujimura et al., 1994) and antral hypomotility has been shown in either GU or duodenal ulcer (DU) patients (Garrett et al., 1966; Stanghellini et al., 1992). Gastric emptying has been reported to be delayed in GU patients (Fujimura et al., 1994; Harasawa et al., 1979; Kamiya et al., 1998), whereas in studies involving DU patient it was accelerated (Harasawa et al., 1979; Maddern et al., 1985; Konturek et al., 1994), particularly after a liquid meal, and in others it was delayed (Kerrigan et al., 1991) or unchanged (Heading et al., 1976; Howlett et al., 1976; Malagelada et al., 1977). In most studies, gastric motility was measured during the active stage in both types of ulcers. No direct comparative evaluation of gastric motility between GU and DU patients has been published. Furthermore, there have been few comparisons of gastric motility between the active and healed stages for both types of ulcers. In the present study, we measured gastric myoelectrical activity in patients with recurrent GU or DU to characterize gastric motility, and then compared the motility patterns in the active stage with those in the healed stage.

\section{Methods}

\section{Subjects}

Studies were performed in 59 patients with recurrent active peptic-ulcer disease as diagnosed by upper gastrointestinal endoscopy and from their detailed histories. All patients had a past history of treatment for two or more peptic ulcers. Thirty-one patients (19 males, 12 females) had GU and 28 patients (19 males, 9 females) had DU. Patients were excluded from this study if they had a known history of cardiovascular disorder, diabetes, collagen disease or any other condition that may result in gastric dysmotility. Patients who had also undergone previous surgery involving the upper gastrointestinal tract were also excluded. None of the patients had previously received therapy for eradication of Helicobacter pylori. Written informed consent was obtained from all patients. In all patients, gastric myoelectical activity was measured during the active stage before treatment, and again after 8 weeks of oral treatment with a proton-pump inhibitor (lansoprazole $30 \mathrm{mg} /$ day or omeprazole $20 \mathrm{mg} /$ day).

\section{Experimental procedure}

Gastric myoelectrical activity was assessed by cutaneous-recorded electro-gastrography (EGG). After fasting for at least 4 hours, the EGG was recorded for $30 \mathrm{~min}$ in the supine position. The subjects then sat up and ingested $200 \mathrm{ml}$ of a semi-liquid test meal (containing 9.8 $\mathrm{g}$ protein, $5.8 \mathrm{~g}$ fat, $28.6 \mathrm{~g}$ carbohydrate, and an energy content of $200 \mathrm{kcal}$; Okunos-A, Okuno, Tokyo, Japan). Following the intake, the subjects immediately returned to the supine position and the EGG was recorded for a further $30 \mathrm{~min}$. The EGG was recorded using bipolar $\mathrm{Ag}-\mathrm{AgCl}$ electrodes placed on the right and left midclavicular lines along the long axis of the stomach over the surface of the upper abdomen. The EGG signals were low-pass filtered with a cut-off frequency of $0.1 \mathrm{~Hz}$, and recorded on an FM data recorder (MR-30, TEAC,Tokyo, Japan). The data obtained were sampled at $1 \mathrm{kHz}$ using an analog-to-digital converter (ADX-98E, Canopus 
Electronics, Kobe, Japan). The following parameters were obtained from the EGG using autoregressive power spectral analyses and evaluated for each subject.

1. EGG dominant frequency: the frequency at which the power was highest within the range of $0.02-0.08 \mathrm{~Hz}(1.2-6.4 \mathrm{cpm})$ for an entire EGG recording. It has been suggested that the dominant frequency of the EGG reflects the frequency of gastric slow waves (Familoni et al., 1991; Chen et al., 1994a, b).

2. Percentage of normogastria: defined as the percentage of time during which normal 0.04$0.06 \mathrm{~Hz}(2.4-3.6 \mathrm{cpm})$ slow waves were present over the entire observation period. This parameter reflects the regularity of gastric myoelectrical activity. An EGG frequency higher than $0.06 \mathrm{~Hz}(3.6 \mathrm{cpm})$ was defined as tachygastria and one slower than $0.04 \mathrm{~Hz}(2.4 \mathrm{cpm})$ was defined as bradygastria.

3. EGG Power ratio: defined as the ratio of postprandial to fasting EGG dominant power values (i.e., postprandial power/fasting power), where the dominant power refers to the power at the EGG dominant frequency. It is suggested that changes in the EGG dominant power reflect gastric contractility (Smout et al., 1980; Hamilton et al., 1986; Chen et al., 1994a, b).

4. Postprandial dip (PD): a transient frequency decrease that is usually seen in the EGG in normal subjects immediately after food intake (Geldof et al., 1986a, b; Kaneko et al., 1995). In this study it was determined by visual inspection.

\section{Statistical analysis}

Values of EGG parameters are expressed as the mean $\pm \mathrm{SD}$ for each group. Intra group changes were analyzed using paired $t$-tests. Inter group comparisons were performed using unpaired $t$-tests. The occurrence of a PD was assessed using a chi-squared test, except where there were fewer than ten data points when a Yates chi-squared test was used. A probability value of $\mathrm{P}<0.05$ was considered to be statistically significant.

\section{Results}

\section{Background factors}

Table 1 shows the clinical characteristics of all patients. The patients in the GU group (19 males and 12 females, 20-61 years old) had one to five ulcers each. H. pylori infection was diagnosed by microscopy, culture, and rapid urease testing of specimens biopsied during endoscopy. When any of the tests were positive, the patient was diagnosed as $H$. pylori positive. Twenty-six patients were positive and five were negative, and two of the latter were being treated with an oral nonsteroidal anti-inflammatory drug (NSAID). The patients in the DU group (19 males and 9 females, 18-59 years old) had one to three ulcers each. Twenty-five of these patients were positive for $H$. pylori and three were negative, and one of the latter was being treated with an oral NSAID. All patients in both groups had experienced two or more recurrences of ulcers.

\section{Electro-gastrography}

Endoscopic examination following 8 weeks of oral medication revealed that the ulcers were 
Table 1 Clinical characteristics of patients

\begin{tabular}{lcc}
\hline & GU group (n=31) & DU group (n=28) \\
\hline Age (years) & $41.8 \pm 13.1$ & $38.9 \pm 10.7$ \\
Gender (M/F) & $19 / 12$ & $19 / 9$ \\
Number of ulcers (/person) & $1.89 \pm 0.98$ & $1.55 \pm 0.69$ \\
Ulcer history (times) & $3.01 \pm 1.18$ & $3.91 \pm 2.12$ \\
Location of ulcers & A 9 & D 28 \\
& B 17 & \\
Helicobacter pylori & C 5 &
\end{tabular}

Helicobacter pylori

$\begin{array}{lll}\text { Status (+/-) } 25 / 5 & 26 / 5\end{array}$

$\overline{\text { Values are mean } \pm \text { SD. GU, gastric ulcer; DU, duodenal ulcer. A, lower }}$ body; B, angulus; C, pyloric part; D, duodenal bulbus.

Table 2 EGG parameters in patients with gastric ulcer

\begin{tabular}{lcc}
\hline & Active stage & Healed stage \\
\hline Fasting EGG & & \\
Dominant frequency (cpm) & $2.94 \pm 0.56$ & $2.89 \pm 0.51$ \\
Normogastria (\%) & $56.4 \pm 7.1$ & $59.5 \pm 9.3$ \\
Tachygastria (\%) & $25.5 \pm 5.7$ & $23.8 \pm 6.1$ \\
Bradygastria (\%) & $18.5 \pm 7.2$ & $17.2 \pm 6.3$ \\
Postprandial EGG & & \\
Dominant frequency (cpm) & $3.17 \pm 0.89$ & $3.13 \pm 0.44$ \\
Normogastria (\%) & $51.9 \pm 7.1$ & $56.7 \pm 6.1$ \\
Tachygastria (\%) & $25.5 \pm 4.9$ & $23.9 \pm 8.5$ \\
Bradygastria (\%) & $22.6 \pm 6.5$ & $20.0 \pm 6.7$ \\
Power ratio & $1.84 \pm 0.79$ & $2.01 \pm 0.62$ \\
Postprandial dip (person) & 9 & 14
\end{tabular}

$\overline{\text { Values are mean } \pm \text { SD. EGG, electrogastrography; cpm, cycle per }}$ minute.

in the healed stage in all 59 patients in both groups. In the GU group, the percentage of normogastria and dysrhythmia in the EGG frequency remained almost unchanged between the active stage and the healed stage in both fasting and postprandial states (Table 2, Fig. 1, Fig. 2). No significant changes were observed in the EGG power ratio after treatment (Fig. 3). In the DU group, the percentage of normogastria and the power ratio of the EGG were significantly increased after treatment (Table 3). During the healed stage, the EGG power ratios in the DU group were significantly higher than in the GU group. During the active stage, a PD was observed in nine GU patients and seven DU patients. During the healed stage, a PD was observed in $13 \mathrm{GU}$ patients, with no significant change observed after treatment. In contrast, in the DU group, the number of patients exhibiting PD increased significantly to 18 after treatment (Fig. 4).

\section{Discussion}

Disturbed gastric myoelectrical activity was detected in this study using EGG in patients with recurrent GU and DU and this activity was different in these two groups of patients. EGG 


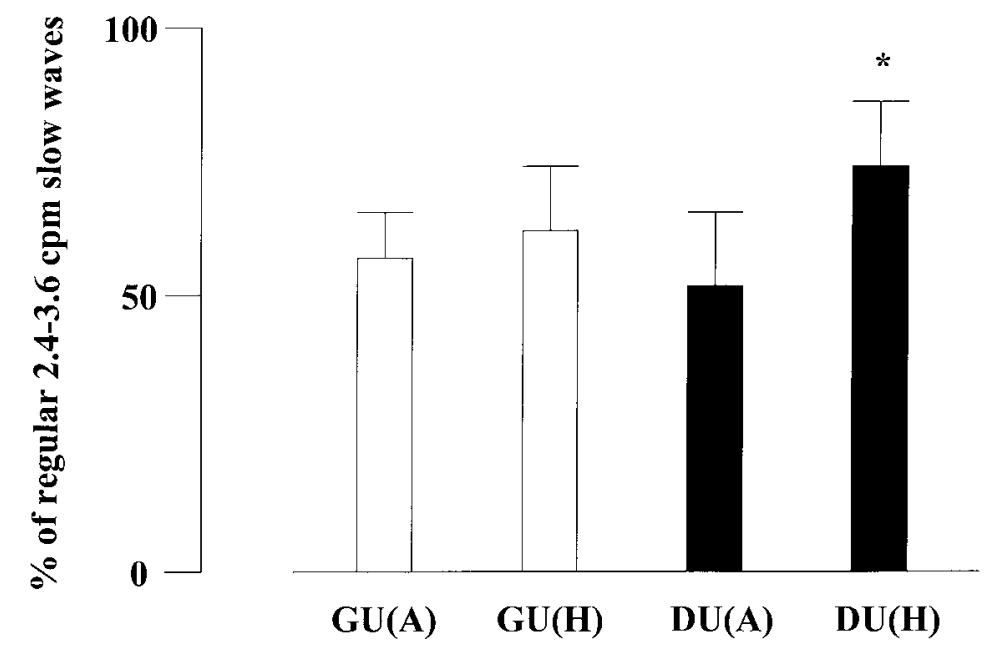

Fig. 1. The percentage of normogastria (regular $2.4-3.6 \mathrm{cpm}$ slow waves) in patients with gastric ulcers and duodenal ulcers while fasting. GU (A), gastric ulcer active stage; GU $(\mathrm{H})$, gastric ulcer healed stage; DU (A), duodenal ulcer active stage; DU $(\mathrm{H})$, duodenal ulcer healed stage. *, $\mathrm{P}<0.01$ versus pre treatment (duodenal ulcer active stage).
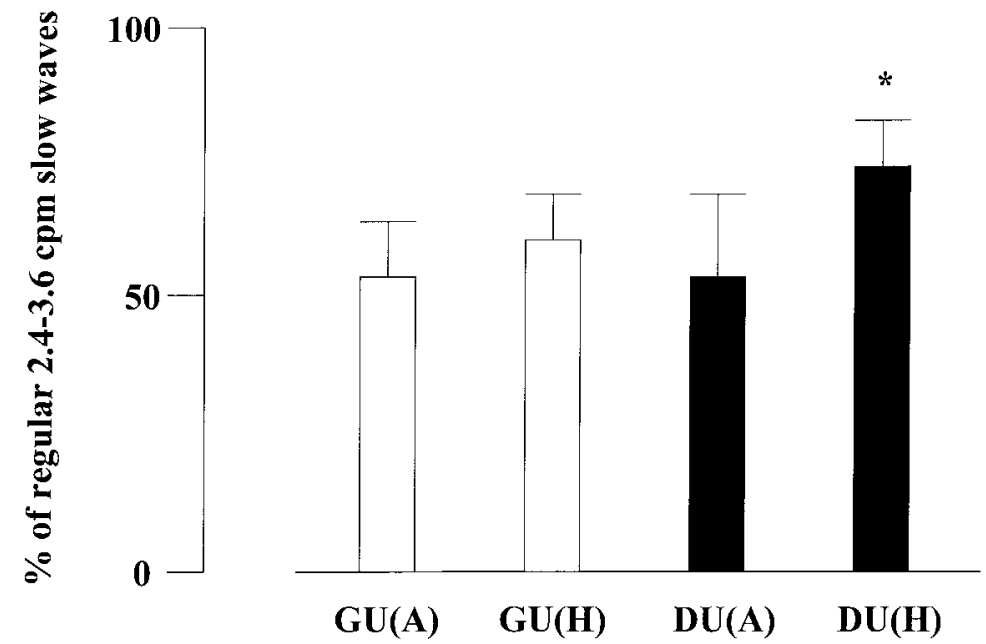

Fig. 2. The percentage of normogastria (regular 2.4-3.6 cpm slow waves) in patients with gastric ulcers and duodenal ulcers after a meal. GU (A), gastric ulcer active stage; GU $(\mathrm{H})$, gastric ulcer healed stage; DU (A), duodenal ulcer active stage; DU $(\mathrm{H})$, duodenal ulcer healed stage. * $\mathrm{P}<0.01$ versus pre treatment (duodenal ulcer active stage).

is a method of recording gastric myoelectrical activity from abdominal surface electrodes (Alvarz, 1922; Geldof et al., 1986a, b; Hamilton et al., 1986). Recent advances in recording devices have led to the wide acceptance of EGG as a simple, non-invasive method for investigating gastric motility. It has been suggested that EGG provides an accurate 


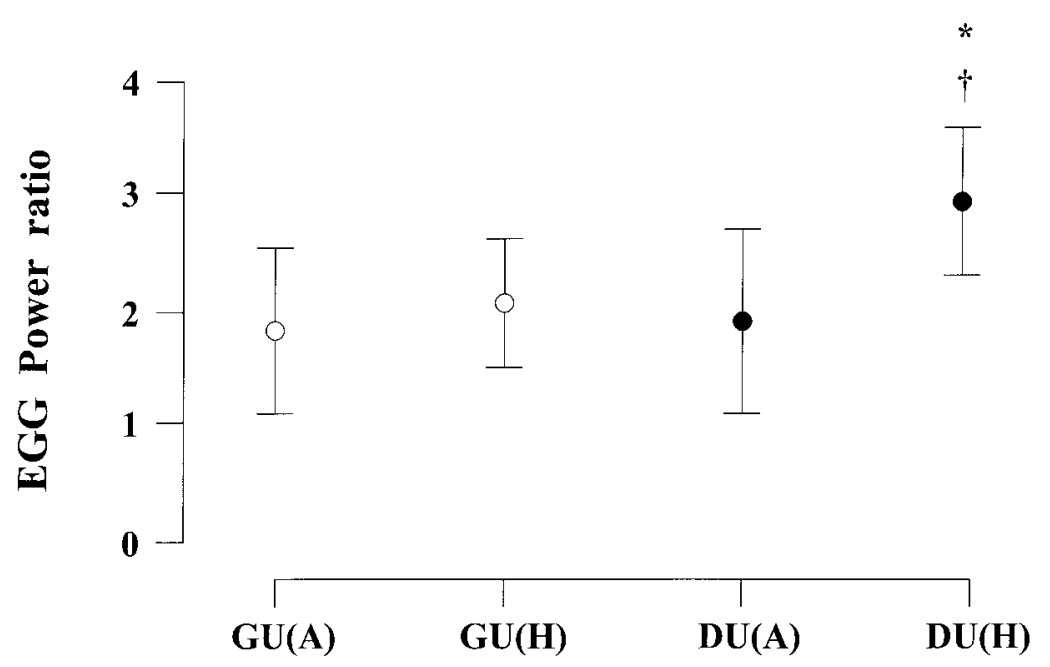

Fig. 3. The EGG power ratio in each group. Error bars indicate the mean \pm SD. GU (A), gastric ulcer active stage; GU (H), gastric ulcer healed stage; DU (A), duodenal ulcer active stage; DU $(\mathrm{H})$, duodenal ulcer healed stage. *, $\mathrm{P}<0.01$ versus pre treatment (duodenal ulcer active stage). $\dagger, \mathrm{P}<0.05$ versus $\mathrm{GU}(\mathrm{H})$ (gastric ulcer healed stage).

Table 3 EGG parameters in patients with duodenal ulcer

\begin{tabular}{lcc}
\hline & Active stage & Healed stage \\
\hline Fasting EGG & & \\
$\quad$ Dominant frequency (cpm) & $3.14 \pm 0.38$ & $3.07 \pm 0.25^{*}$ \\
Normogastria (\%) & $53.1 \pm 10.2$ & $73.9 \pm 8.6$ * \\
Tachygastria (\%) & $26.4 \pm 6.2$ & $14.4 \pm 3.3$ * \\
Bradygastria (\%) & $20.4 \pm 9.2$ & $11.7 \pm 8.9$ * \\
Postprandial EGG & & \\
Dominant frequency (cpm) & $3.19 \pm 0.47$ & $2.95 \pm 0.36^{*}$ \\
Normogastria (\%) & $51.5 \pm 11.4$ & $70.6 \pm 6.6$ * \\
Tachygastria (\%) & $25.8 \pm 9.2$ & $17.5 \pm 1.8$ * \\
Bradygastria (\%) & $22.5 \pm 8.6$ & $12.1 \pm 4.1$ * \\
Power ratio & $1.98 \pm 0.81$ & $2.91 \pm 0.66^{*}$ \\
Postprandial dip (person) & 8 & 21
\end{tabular} *

$\overline{\text { Values are mean } \pm \text { SD. EGG, electrogastrography; cpm, cycle per }}$ minute. ${ }^{\star} \mathrm{P}<0.01$ vs. pre treatment (active stage).

measurement of gastric slow waves, and that an increase in the EGG power reflects contractionrelated spike potentials (Smout et al., 1980; Hamilton et al., 1986). Abnormal gastric myoelectrical activity detected by EGG has been described in patients with non-ulcer dyspepsia (Geldof et al., 1986a, b; Miyaji et al., 1999; Chou et al., 2001), anorexia nervosa (Abell et al., 1987), and diabetes gastropathy (Koch et al., 1989). Various electrical abnormalities have been detected, such as abnormal high (tachygastria) or low (bradygastria) slow-wave frequency, and a smaller postprandial increase in EGG power. Although the correlation between the waveform in the EGG and actual gastric contraction requires further investigation, we suggest that EGG abnormalities indicate abnormal or reduced gastric contraction and a disturbance in gastric 


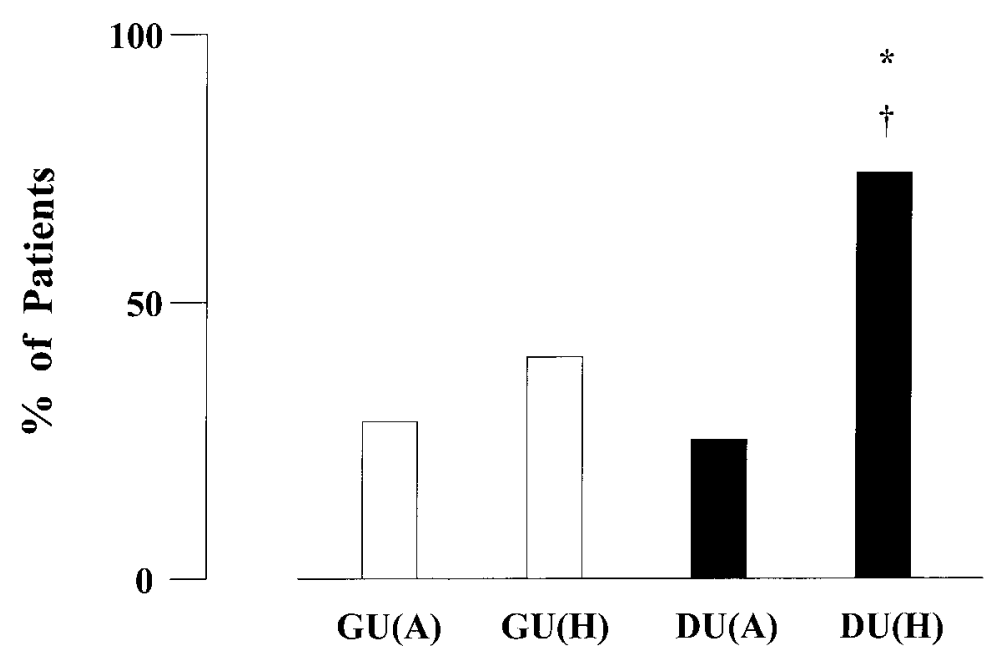

Fig. 4. The proportion of patients with gastric ulcers and duodenal ulcers demonstrating postprandial dip. GU (A), gastric ulcer active stage; $G U(H)$, gastric ulcer healed stage; DU (A), duodenal ulcer active stage; DU (H), duodenal ulcer healed stage. *, $\mathrm{P}<0.01$ versus pre treatment (duodenal ulcer active stage). $\dagger, \mathrm{P}<0.05$ versus $\mathrm{GU}(\mathrm{H})$ (gastric ulcer healed stage).

motility.

The findings of the present study suggest that the abnormalities of gastric myoelectrical activity in GU are not only result from the GU itself, but are also a factor in their onset and recurrence. In the GU group, no significant improvement in the percentage of normogastria and in the EGG power ratio was observed during the healed stage compared with those during the active stage. The occurrence of PD, which has been reported to be detectable in the EGG of normal subjects, was almost unchanged after treatment. These results suggest that disturbed gastric myoelectrical activity-which is present even during the healed stage-is one component that is responsible for the recurrence of GU. Geldof et al. (1989) using EGG reported that abnormal gastric myoelectrical activity was found in patients with an active GU, and this disappeared with ulcer healing. This contrasts with the findings of the present study, which may be due to differences in the patients' backgrounds (e.g., ulcer location, and whether it was recurrent).

In the DU group, the percentage of normogastria, the EGG power ratio, and the occurrence of PD were significantly increased during the healed stage compared with those observed during the active stage. These results indicate that the gastric myoelectrical activity was significantly improved after the treatment. Kerriga et al. (1991) reported that patients with active and healed DU have disturbed gastroduodenal motility and that patients with healed DU show significantly retarded gastric emptying compared with active DU and controls. They suggested that disturbed coordinated gastroduodenal motility may promote ulcer relapse by impairing acid clearance in the duodenal bulbus. Once the ulcer heals, motility remains disturbed in a small fraction of the DU patients. Apparently, in some patients the DU is primary, whereas in others the dysmotility is primary. 
The results from the present study suggest that abnormal gastric myoelectrical activity plays an important role in the pathophysiology of recurrent GU, but not DU. In the GU group, gastric myoelectrical activity was not improved during the healed stage, whereas it did improve significantly in the DU group. Furthermore, during the healed stage, the percentage of normogastria, the power ratio and the occurrence of PD were significantly lower in the GU group than in the DU group. It has been reported previously that a postprandial increase in the EGG power seems to be related to an increase in the gastric contraction and accelerated gastric emptying. Because the retention of gastric contents may stimulate gastric acid secretion, the disturbed gastric motility after food intake is suggested to be a factor in GU recurrence.

A correlation between $H$. pylori infection and the onset and recurrence of peptic ulcers was reported recently. In the present study, 26 of 31 patients with GUs and 25 of 28 patients with DUs were $H$. pylori positive. The effect of $H$. pylori infection on gastric motility is unclear, with many studies showing (Rokkas et al., 1987; Kao et al., 1997; Pfaffenbach et al., 1997) little direct relation between $H$. pylori infection and gastric motility. However, Tucci et al. (1992) reported that $H$. pylori-negative patients with idiopathic dyspepsia had gastric emptying times that were significantly slower than those of both $H$. pylori-positive patients and healthy controls. In contrast, Fock et al. (1997) reported that gastric emptying was significantly slower in $H$. pyloripositive dyspeptic patients than in $H$. pylori-negative dyspeptic patients. Correlating abnormalities in gastrointestinal motility with the onset and recurrence of ulcers and with $H$. pylori infection requires further investigation.

In conclusion, disturbed gastric myoelectrical activity was detected in patients with recurrent GU and DU, and this abnormal activity was suggested to play an important role in the pathophysiology of recurrent GU rather than DU.

\section{References}

Abell, T.L., Malagelada, J.R., Lucas, A.R., Brown, M.L., Camilleri, M., Go, V.L.W., Azpiroz, F., Callaway, C.W., Kao, P.C., Zinsmeister, A.R and Huse, D.M. (1987). Gastric electromechanical and neurohormonal function in anorexia nervosa. Gastroenterol. 93: 958-965.

Alvarez, W.C. (1922). New methods of studying gastric peristalsis. JAMA 79: 1281-1285.

Chen, J.D.Z., Schirmer, B.D. and McCallum, R.W. (1994a). Serosal and cutaneous recordings of gastric myoelectrical activity in patients with gastroparesis. Am. J. Physiol. 266: G90-G98.

Chen, J.D.Z., Richards, R.D. and McCallum, R.W. (1994b). Identification of gastric contractions from the cutaneous electrogastrogram. Am. J. Gastroenterol. 89: 79-85.

Chou, L.T., Wu, C.Y., Chen, H.P., Chang, C.S., Wong, P.G., Ko, C.W. and Chen, G.H. (2001). The correlation of depression and gastric dysrhythmia in functional dyspepsia. J. Clin. Gastroenterol. 33: 127-131.

Familoni, B.O., Bowes, K.L., Kingma, Y.J. and Cote, K.R. (1991). Can transcutaneous recordings detect gastric electrical abnormalities? Gut. 32: 141-146.

Fock, K.M., Khoo, T.K., Chia, K.S. and Sim, C.S. (1997). Helicobacter pylori infection and gastric emptying of indigestible solids in patients with dysmotility-like dyspepsia. Scand. J. Gastroenterol. 32: 676-680.

Fujimura, J., Haruma, K., Hata, J., Yamanaka, H., Sumii, K. and Kajiyama, G. (1994). Quantitation of duodenogastric reflux and antral motility by color doppler ultrasonography. Scand. J. 
Gastroenterol. 29: 897-902.

Garrett, J.M., Summerskill, W.H.J. and Code, C.F. (1966). Antral motility in patients with gastric ulcer. Am. J. Dig. Dis. 11: 780-789.

Geldof, H., van der Schee, E.J., van Blankenstein, M. and Grashuis, J.L. (1986a). Electrogastrographic study of gastric myoelectrical activity in patients with unexplained nausea and vomiting. Gut. 27: 799-808.

Geldof, H., van der Schee, E.J. and Grashuis, J.L. (1986b). Electrogastrographic characteristics of interdigestive migrating complex in humans. Am. J. Physiol. 250: G165-G171.

Geldof, H., van der Schee, E.J., Smout, A.J.P.M., van de Merwe, J.P., van Blankenstein, M. and Grashuis, J.L. (1989). Myoelectrical activity of the stomach in gastric ulcer patients: an electrogastrographic study. J. Gastrointest. Motil. 1: 122-130.

Hamilton, J.W., Bellahsene, B.E., Reichelderfer, M., Webster, J.G. and Bas, P. (1986). Human electrogastrograms. Comparision of surface and mucosal recordings. Dig. Dis. Sci. 31: 33-39.

Harasawa, S., Tani, N., Suzuki, S., Miwa, M., Sakita, R., Nomiyama, T. and Miwa, T. (1979). Gastric emptying in normal subjects and patients with peptic ulcer. Gastroenterologia Jpn. 14: 1-10.

Heading, RC., Tothill, P., Mcloughlin, G.P. and Shearman, D.J.C. (1976). Gastric emptying rate measurment in man. Gastroenterol. 71: 45-50.

Howlett, P.J., Sheiner, H.J., Barber, D.C., Ward, A.S., Perez-Avila, C.A. and Duthie, H.L. (1976). Gastric emptying in control subjects and patients with duodenal ulcer before and after vagotomy. Gut. 17: 542-550.

Kamiya, T., Nagao, T., Ando, T., Misu, N. Kobayashi, Y., Hirako, M., Hara, M. and Fujinami, T. (1998). Effects of trimebutine maleate on gastric motility in patients with gastric ulcer. J. Gastroenterol. 33: 823-827.

Kaneko, H., Sakakibara, M., Mitsuma, T. and Morise, K. (1995). Possibility of postprandial electrogastrography for evaluating vagal/nonvagal cholinergic activity in humans, through simultaneous analysis of postprandial heart rate variability and serum immunoreactive hormone levels. Am. J. Gastroenterol. 90: 603-609.

Kao, CH., Wang, S.J., Chen, G.H. and Yeh, S.H. (1997). The relationship between Helicobacter pyloriassociated gastritis or ulcer disease and gastric emptying. Eur. J. Nucl. Med. 21: 209-211.

Kerrigan, D.D., Read, N.W., Houghton, L.A., Taylor, M.E. and Johnson, A.G. (1991). Disturbed gastroduodenal motility in patients with active and healed duodenal ulceration. Gastroenterol. 100: 892-900.

Koch, K.L., Stern, R.M., Stewart, W.R. and Vasey, M.W. (1989). Gastric emptying and gastric myoelectrical activity in patients with diabetic gastroparesis: effect of long-term domperidone treatment. Am. J. Gastroenterol. 84: 1069-1075.

Konturek, J.W., Thor, P., Maczka, M., StolI.R., Domschke, W. and Konturek, S.J. (1994). Role of cholecystokinin in the control of gastric emptying and secretory response to a fatty meal in normal subjects and duodenal ulcer patients. Scand. J. Gastroenterol. 29: 583-590.

Maddern, G.J., Horowitz, M,. Hetzel, D.J. and Jamieson, G.G. (1985). Altered solid and liquid gastric emptying in patients with duodenal ulcer disease. Gut. 26: 689-693.

Malagelada, J.R., Longstreth, G.F., Deering, T.B., Summerskill, W.H.J. and Go, V.L.W. (1977). Gastric secretion and emptying after ordinaly meals in duodenal ulcer. Gastroenterol. 73: 989-994.

Miranda, M., Defilippi, C. and Valenzuela, J.E. (1985). Abnormalities of interdigestive motility complex and increased duodenogastric reflux in gastric ulcer patients. Dig. Dis. Sci. 30: 16-21.

Miyaji, H., Azuma, T., Ito, S., Abe, Y., Ono, H., Suto, Y., Ito, Y., Yamazaki, Y., Kohli, Y. and Kuriyama, M. (1999). The effect of Helicobacter pylori eradication therapy on gastric antral myoelectrical activity and gastric emptying in patients with non-ulcer dyspepsia. Aliment. Pharmacol. Ther. 13: 1473-1480.

Pfaffenbach, B., Adamek, R.J., Bartholomaus, C. and Wegener, M. (1997). Gastric dysrhythmias and 
delayed gastric emptying in patients with functional dyspepsia. Dig. Dis. Sci. 42: 2094-2099.

Rokkas, T., Pursey, C., Uzoechina, E., Dorrington, L., Simmons, N.A., Filipe, M.I. and Sladen, G.E. (1987). Campylobacter pylori and non-ulcer dyspepsia. Am. J. Gastroenterol. 82: 1149-1152.

Smout, A.J.P.M., van der Schee, E.J. and Grashuis, J.L. (1980). What is measured in electrogastrography? Dig. Dis. Sci. 25: 179-187.

Stanghellini, V., Ghidini, C., Maccarini, M.R., Paparo, G.F., Corinaldesi, R. and Barbara, L. (1992). Fasting and postprandial gastrointestinal motility in ulcer and non-ulcer dyspepsia. Gut. 33: 184-190.

Tucci, A., Corinaldesi, R., Stanghellini, V., Tosetti, C., Di Febo, G., Paparo, G.F., Varoli, O., Paganelli, G.M., Labate, A.M.M., Masci, G., Zoggoli, G., Monetti, N. and Barbara, L. (1992). Helicobacter pylori infection and gastric function in patients with chronic idiopathic dyspepsia. Gastroenterol. 103: 768-774.

(Received February 26, 2003: Accepted March 12, 2003) 